\title{
Isolated extramedullary breast relapses in inv(16) positive and c-KIT negative acute myeloid leukemia after allogenic hematopoietic stem cell transplantation - description of two cases
}

\author{
Anna Szumera-Ciećkiewicz르, Barbara Nasilowska-Adamska², Monika Prochorec-Sobieszek \\ Katarzyna Borg ${ }^{1}$, Mirosław Markiewicz ${ }^{3}$, Bożena Mariańska¹, Krzysztof Warzocha ${ }^{4}$
}

\author{
${ }^{1}$ Department of Diagnostic Hematology, Institute of Hematology and Transfusion \\ Medicine, Warsaw, Poland \\ ${ }^{2}$ Department of Hematopoietic Stem Cell Transplantation, Institute of Hematology \\ and Transfusion Medicine, Warsaw, Poland \\ ${ }^{3}$ Department of Hematology and Bone Marrow Transplantation, Silesian Medical \\ Institute, Katowice, Poland \\ ${ }^{4}$ Department of Hematology, Institute of Hematology and Transfusion Medicine, \\ Warsaw, Poland
}

Submitted: 30 July 2013

Accepted: 12 September 2013

Arch Med Sci 2014; 10, 3: 632-635

DOI: 10.5114 /aoms.2014.43756

Copyright (c) 2014 Termedia \& Banach

According to the WHO classification acute myeloid leukemia (AML) is categorized according to cytogenetic and molecular changes [1]. The subgroups with adverse, intermediate and favorable genetics were redefined and incorporated into the major factors predicting treatment-related mortality. Postremission therapy strategies are basically related to cytogenetic abnormalities; therefore for patients with favorable-risk AML repetitive cycles of high-dose cytarabine are considered superior to autologous or allogenic hematopoietic stem cell transplantation (auto- or allo-HSCT) [2, 3].

The AML rarely may present in extramedullary form as a primary disease called myeloid sarcoma or as extramedullary relapse (EMR). In recent studies, EMR incidence following allo-HSCT is estimated to be from $5 \%$ to $11 \%$ and occurs in "sanctuary" sites, e.g. central nervous system, ovary and testis, as well as other anatomical locations including skin, muscle, body cavities, mammary glands, gastrointestinal tract and urinary tract [4-7]. Up to 2010 as many as 163 cases of AML breast relapse were described but only $36 \%$ had karyotype evaluation [8]. We present two patients with AML favorable cytogenetics - inv(16)(p13;q22); CBFB (core binding factor $\beta$-chain)-MYH11 (myosin heavy chain 11 gene) - and EMR in breast after allo-HSCT.

Case 1. AML M2 according to the French-American-British (FAB) classification with $\operatorname{inv}(16)(\mathrm{p} 13 ; \mathrm{q} 22)$ and without FLT3(Fms-like tyrosine kinase 3)-ITD(internal-tandem duplications) mutation was diagnosed in a 33-year-old female (Table I). She underwent induction chemotherapy according to the DAC-7 protocol (daunorubicin $60 \mathrm{mg} / \mathrm{m}^{2} /$ day i.v., days 1-3; cytarabine $200 \mathrm{mg} / \mathrm{m}^{2} /$ day, days $1-7$; cladribine $5 \mathrm{mg} / \mathrm{m}^{2} /$ day, days 1-5) and consolidation (HAM: cytarabine $1.5 \mathrm{~g} / \mathrm{m}^{2} /$ day i.v., days 1-3; mitoxantrone $10 \mathrm{mg} / \mathrm{m}^{2}$, days $3-5$ and HD-Ara-C regime: cytarabine $2 \mathrm{~g} / \mathrm{m}^{2}$ i.v., days $1,3,5)$. Complete haematological, cytogenetic and molecular re-

\author{
Corresponding author: \\ Anna Szumera-Ciećkiewicz \\ MD, PhD \\ Department of Diagnostic \\ Hematology \\ Institute of Hematology \\ and Transfusion Medicine \\ 14 Gandhi St \\ 02-776 Warsaw, Poland \\ Phone: +48604192787 \\ E-mail: szumann@gmail.com
}


mission (CR) was achieved. Subsequently, 4 cycles of maintenance chemotherapy were administered and the patient was qualified for allo-HSCT from an HLA-matched sibling because of molecular relapse. The myeloablative conditioning regimen included busulfan i.v. (3.2 mg/kg/day, days -8 to -5 ) and cyclophosphamide (60 mg/kg/day, days -4 to -2 ). Graft-versus-host disease (GvHD) prophylaxis with cyclosporine A (3 mg/kg/day i.v. from -1 day) and methotrexate $\left(15 \mathrm{mg} / \mathrm{m}^{2}\right.$, day +1 and $10 \mathrm{mg} / \mathrm{m}^{2}$, days $+3,+6,+11$ ) was provided. After transfusion of peripheral blood stem cells (PBSC) consisting of 9.5 $\times 10^{6} \mathrm{CD} 34+$ cells $/ \mathrm{kg}$, bone marrow regeneration was achieved (WBC > $1.0 \times 10^{9} /$ l on day +13 , ANC > $0.5 \times 10^{9} /$ / on day +17 , PLT $>20 \times 10^{9} /$ l on day +9 , $\mathrm{PLT}>50 \times 10^{9} /$ l on day +11 ). The post-allo-HSCT period elapsed without signs of GVHD. She was in hematological, cytogenetic and molecular CR with $100 \%$ donor chimerism tested with STR-PCR (short tandem repeats-polymerase chain reaction). Breast relapse of $A M L$ was diagnosed 25 and 11 months after initial diagnosis and allo-HSCT, respectively. Computed tomography (CT) revealed a polycystic, solid tumor mass of the right breast $70 \mathrm{~mm} \times 65 \mathrm{~mm}$ $\times 32 \mathrm{~mm}$ in size (Figure $1 \mathrm{~A}$ ). The histopathological examination of tumor biopsy (Figures $1 \mathrm{~B}$ and $1 \mathrm{C}$ ) and cytogenetic evaluation (Figures $1 \mathrm{D}$ and $1 \mathrm{E}$ ) confirmed the AML EMR. Concurrently, molecular relapse was detected as the leukemia-specific CBFB-MYH11 transcript was identified but still 100\% donor chimerism was maintained. Chemotherapy with Ida-FLAG protocol (idarubicin $12 \mathrm{mg} / \mathrm{m}^{2}$, days 2-4; fludarabine $30 \mathrm{mg} / \mathrm{m}^{2}$, days 1-4; cytarabine $2000 \mathrm{mg} / \mathrm{m}^{2}$, days $1-4$ and G-CSF up to ANC > 1 $\times 10^{9} / \mathrm{l}, 400 \mu \mathrm{g} / \mathrm{m}^{2}$, day 0$)$ was administered. The molecular CR was obtained and partial regression of breast tumor was observed in CT. Consolidation with the HAM regimen and radiotherapy to the chest field with total 4000 cGy (20 fractions) were performed. The bone marrow and breast CR was maintained in 15 and 11 months follow-up. The retrospective analyses (direct sequencing) of the c-KIT gene mutation, exons 8 and 17, were negative in bone marrow aspirated at the time of diagnosis and breast EMR infiltration.

Case 2. AML M4EO, FLT3-ITD negative, was diagnosed in a 32-year-old female (Table I). The induction treatment started with DAF (daunorubicin $60 \mathrm{mg} / \mathrm{m}^{2}$, days $1-3$; cytarabine $200 \mathrm{mg} / \mathrm{m}^{2}$, days $1-7$ and fludarabine $25 \mathrm{mg} / \mathrm{m}^{2}$, days $1-5$ ). Consolidation according to the HAM and HD-AraC regimens was performed with haematological, cytogenetic and molecular CR achievement. Subsequently, 8 cycles of maintenance chemotherapy were administered. As the first relapse occurred, the patient was given DAF reinduction followed with HAM consolidation, which initiated the next CR. Allo-HSCT from an HLA-identical unrelated donor was per- formed with myeloablative conditioning: treosulfan (14 $\mathrm{mg} / \mathrm{m}^{2} /$ day, days 6 to -4 ), fludarabine (35 mg/m²/day, days -6 to -2 ) and anti-thymocyte globulin (ATG) at a total dose of $15 \mathrm{mg} / \mathrm{kg}$, days -3 to -1 . Then she received $10 \times 10^{6} \mathrm{CD} 34+\mathrm{PBSC} /$ kg. For GvHD prophylaxis the same treatment was

Table I. Characteristics of patients at initial diagnosis and features of breast extramedullary relapses

\begin{tabular}{|c|c|c|}
\hline Parameter & Case 1 & Case 2 \\
\hline \multicolumn{3}{|c|}{ Characteristics of patients at diagnosis } \\
\hline Age [years] & 33 & 32 \\
\hline ECOG & 1 & 1 \\
\hline WBC $\left[\times 10^{9} / 1\right]$ & 100.903 & 9.53 \\
\hline $\operatorname{PLT}\left[\times 10^{9} / 1\right]$ & 25.2 & 37 \\
\hline HGB [g\%] & 9.5 & 8.5 \\
\hline $\begin{array}{l}\text { Extramedullary } \\
\text { involvement at } \\
\text { diagnosis }\end{array}$ & No & No \\
\hline $\begin{array}{l}\text { Blasts in peripheral } \\
\text { blood }(\%)\end{array}$ & 78 & 63 \\
\hline $\begin{array}{l}\text { Blasts in bone marrow } \\
\text { flow cytometry }(\%)\end{array}$ & 65 & 51 \\
\hline \multicolumn{3}{|c|}{ Immunophenotype in flow cytometry (\%): } \\
\hline CD13 & 97.1 & NS \\
\hline CD15 & $N S^{*}$ & NS \\
\hline CD33 & 40.4 & 64 \\
\hline CD34 & 99.0 & 80 \\
\hline CD45 & NS & 100 \\
\hline CD117 & 95.5 & 95 \\
\hline HLA-DR & 86.4 & NS \\
\hline MPO & 92.2 & NS \\
\hline Disease (FAB) & AML M2 & AML M4Eo \\
\hline Cytogenetics & $\begin{array}{c}\operatorname{inv}(16) \\
(\mathrm{p} 13 ; \mathrm{q} 22) ; \\
\text { CBFB-MYH11 }\end{array}$ & $\begin{array}{c}\operatorname{inv}(16) \\
(p 13 ; q 22) ; \\
\text { CBFB-MYH11 }\end{array}$ \\
\hline \multicolumn{3}{|l|}{ Molecular evaluation : } \\
\hline FLT3-ITD & Negative & Negative \\
\hline$c-K I T$, exons 8 and 17 & Negative & Negative \\
\hline \multicolumn{3}{|c|}{ Characteristics of breast extramedullary relapse (ER) } \\
\hline Time to ER [months] & 25 & 48 \\
\hline Localization & $\begin{array}{c}\text { Unilateral } \\
\text { (right breast) }\end{array}$ & Bilateral \\
\hline $\begin{array}{l}\text { Previous acute or } \\
\text { chronic GvHD }\end{array}$ & No & $\begin{array}{l}\text { Yes (skin, } \\
\text { gastrointes- } \\
\text { tinal tract) }\end{array}$ \\
\hline $\begin{array}{l}\text { Bone marrow relapse } \\
\text { (BMR) }\end{array}$ & Yes $^{\star *}$ & Yes \\
\hline Time to BMR [months] & 25 & 19 \\
\hline
\end{tabular}

${ }^{*}$ Not significant, ${ }^{* *}$ molecular relapse 

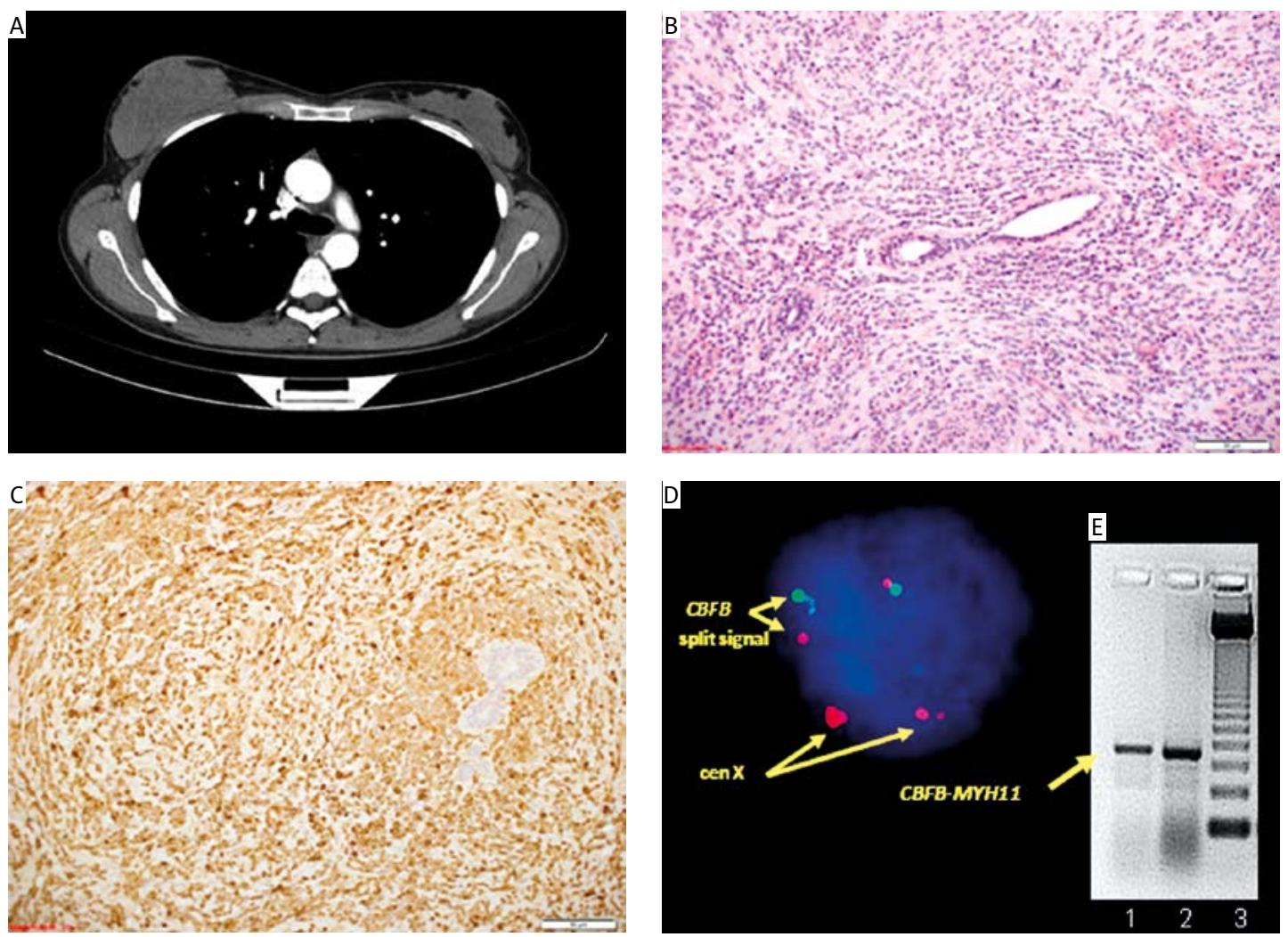

Figure 1. Breast extramedullary relapse imaging (Case 1): computed tomography (A), microscopic (B - proliferation of blast cell with scant cytoplasm and round-oval nuclei with dispersed chromatin and small nucleoli; epithelial structures such as ducts and lobules were preserved with surrounding neoplastic cells (H + E stain, 200x); C - blastic cells strongly express myeloperoxidase (EnVision stain, 200x)) and cytogenetic characteristics (D - result of interphase FISH analysis with CBFB DC Break Apart Probe and CEPX(DXZ1)/Y(DYZ1) (Vysis) show female cell (2 centromere $X$ signals) with separate signals of $C B F B$ gene split apart due to the inversion; $E$ - fusion transcript CBFB-MYH11 type A detected by RT-PCR in examined material (line 1), positive control with RNA isolated from BM cells of another AML M4 patient (line 2), 123 bp marker (line 3))

provided as in Case 1. Complete hematological reconstitution was accomplished (WBC $>1.0 \times 10^{9} / \mathrm{l}$ on day +12 , ANC $>0.5 \times 10^{9} / /$ on day +11 , PLT $>20 \times 10^{9} /$ I on day +11 , PLT > $50 \times 10^{9} /$ I on day +17 ). Acute GvHD (skin - grade III, gastrointestinal tract - grade II according to the Glucksberg clinical classification [9]) was diagnosed on day +9 . Additional immunosuppressive treatment with steroid (methylprednisolone) was applied at a dose of $2.5 \mathrm{mg} / \mathrm{kg}$ a day and was slowly tapered with complete withdrawal on day +42 following allo-HSCT. Nevertheless, isolated mucosal chronic GvHD persisted. The patient remained in hematological, cytogenetic and molecular CR with 100\% donor chimerism tested with the STR-PCR method after allo-HSCT. The EMR concerning entirely both breasts and bone marrow was reported at 48 and 10 months after the initial diagnosis and allo-HSCT respectively. Computed tomography revealed solid tumor masses in both breasts of various sizes. The patient received CLAG-M reinduction (cladribine $5 \mathrm{mg} / \mathrm{m}^{2}$, days $1-5$; cytarabine $2 \mathrm{~g} / \mathrm{m}^{2}$, days $1-5$; G-CSF 300 mg s.c., days 0-5; mitoxantrone $10 \mathrm{mg} /$ $\mathrm{m}^{2}$, days $\left.1-3\right)$, breast radiotherapy with a total dose of 1000 Gy and Ida/Ara-C (idarubicin $10 \mathrm{mg}$ / $\mathrm{m}^{2}$, days $1-3$ and cytarabine $1 \mathrm{~g} / \mathrm{m}^{2}$, days $\left.1-5\right)$ and she achieved CR. The second allo-HSCT from the same unrelated donor $\left(9.52 \times 10^{6} \mathrm{CD} 34+\mathrm{PBSC} / \mathrm{kg}\right)$ with nonmyeloablative conditioning total body irradiation (TBI) (2 Gy on day -3, fludarabine $35 \mathrm{mg}$ / $\mathrm{m}^{2}$ a day, days -4 to -2 ) and ATG (at total dose $25 \mathrm{mg} / \mathrm{kg}$, days -3 to -1 ) was performed 20 months following the first allo-HSCT. Bone marrow regeneration was achieved $\left(\mathrm{WBC}>1.0 \times 10^{9} / \mathrm{l}\right.$ on day +19 , ANC $>0.5 \times 10^{9} / /$ on day +18 , PLT $>20$ $\times 10^{9} /$ l on day +42 , PLT $>50 \times 10^{9} /$ ll on day +55 ). The immunosuppressive therapy was stopped on day +34 following the second allo-HSCT without signs of GvHD. The last relapse was observed at 51 months after the initial diagnosis and 5 months following the second allo-HSCT. This patient died one month later due to septic shock. The results of retrospective direct sequencing of exons 8 and 17 of $c-K I T$ gene mutations in bone marrow sampled at the time of diagnosis and breast relapse tissue were both negative.

In studies to date on EMR after allo-HSCT, several risk factors have been taken into consideration, 
but their comprehensive significance remains unclear. Several factors are thought to be associated with higher incidence of EMR including younger age of patients, extramedullary involvement prior to allo-HSCT, advanced AML, and unfavorable karyotype [10-13]. Moreover, previous GvHD seems to occur more frequently in EMR compared with bone marrow relapse $[6,14]$. The latest meta-analysis of AML extramedullary relapses in the breast, reported by Cunningham [8], included 163 cases published between 1969 and 2010. All FAB subtypes were nearly equally observed, but karyotypes were available only in 55 cases (36\%). In 10 cases (18.2\%) inv(16) was described and the remaining AML karyotypes were: 16 (29.1\%) - normal, $9(16.4 \%)-t(8 ; 21), 3(5.5 \%)-t(15 ; 17), 6$ (10.9\%) $+8,11-$ other complex genetic abnormalities. The immunohistochemical markers on leukemic breast tumors which were expressed in all analyzed cases concerned CD33, CD43, CD45 and HLA-DR, without quantifying the percentage of labeled cells.

In the current literature review no molecular markers characteristic for extramedullary relapses were specified. Such investigations were not performed in a group of good prognosis CBF AML patients with extramedullary breast relapses. Although CBF AML compared with other types of AML showed favorable prognosis, almost 50\% had early relapse presentation and significant differences in overall survival $[15,16]$. The presence of FLT3-ITD or C-KIT mutations was found to be associated with poor prognosis compared to wildtype patients [17]. Both of our patients were negative for FLT3-ITD and frequent $c-K I T$ mutations but the prognosis after breast EMR differed: the first maintained bone marrow and breast CR (15 and 11 months) after consolidation and radiotherapy; the second one died 6 months after chemotherapy, radiotherapy and second allo-HSCT.

In conclusion, we present 2 patients with CBF $\mathrm{AML}$ and development of extramedullary breast relapse after allo-HSCT. Despite similar presentation and molecular marker expression, discrepancies in follow-up were observed. The absence of FLT3-ITD transcript and frequent c-KIT mutations may exclude the use of these adverse molecular markers in extramedullary breast relapses, but to confirm this correlation molecular research on a larger group of CBF AML patients with isolated extramedullary breast relapses is required.

\section{References}

1. Swerdlow S, Campo E, Harris N, et al. (eds.). WHO Classification of tumours of haematopoietic and lymphoid tissues. IARC Press, Lyon 2008.

2. Schlenk RF, Dohner K, Krauter J, et al. Mutations and treatment outcome in cytogenetically normal acute myeloid leukemia. N Engl J Med 2008; 358: 1909-18.
3. Dohner H, Estey EH, Amadori S, et al. Diagnosis and management of acute myeloid leukemia in adults: recommendations from an international expert panel, on behalf of the European LeukemiaNet. Blood 2010; 115: 453-74.

4. Chong G, Byrnes G, Szer J, Grigg A. Extramedullary relapse after allogeneic bone marrow transplantation for haematological malignancy. Bone Marrow Transplant 2000; 26: 1011-5.

5. Lee KH, Lee JH, Kim S, Lee JS, Kim SH, Kim WK. High frequency of extramedullary relapse of acute leukemia after allogeneic bone marrow transplantation. Bone Marrow Transplant 2000; 26: 147-52.

6. Solh M, DeFor TE, Weisdorf DJ, Kaufman DS. Extramedullary relapse of acute myelogenous leukemia after allogeneic hematopoietic stem cell transplantation: better prognosis than systemic relapse. Biol Blood Marrow Transplant 2012; 18: 106-12.

7. Zhai X, Wang H, Zhu X, et al. Gene polymorphisms of $A B C$ transporters are associated with clinical outcomes in children with acute lymphoblastic leukemia. Arch Med Sci 2012; 8: 659-71.

8. Cunningham I. A basis for updating our approach to resistant acute leukemia. Am J Hematol 2012; 87: 251-7.

9. Glucksberg H, Storb R, Fefer A, et al. Clinical manifestation of graft-versus-host disease in human recipients of marrow from HLA-matched sibling donors. Transplantation 1974; 18: 295-304.

10. Halaburda K, Marianska B, Warzocha K, et al. Clinical evaluation of busulfan, cladribine and alemtuzumab as reduced intensity conditioning for stem cell transplantation. Ann Transplant 2009; 14: 7-12.

11. Nasilowska-Adamska B, Majewski M, Seferynska I, et al. Predictive value of RT-PCR PML-RARA transcript monitoring for extramedullary relapse of acute promyelocytic leukemia in the pleura, heart and pericardium after allogeneic SCT. Ann Transplant 2007; 12: 33-8.

12. Kayser S, Dohner K, Krauter J, et al. The impact of therapy-related acute myeloid leukemia (AML) on outcome in 2853 adult patients with newly diagnosed AML. Blood 2011; 117: 2137-45.

13. Lee $\mathrm{KH}$, Lee JH, Choi SJ, et al. Bone marrow vs extramedullary relapse of acute leukemia after allogeneic hematopoietic cell transplantation: risk factors and clinical course. Bone Marrow Transplant 2003; 32: 835-42.

14. Singhal S, Powles R, Kulkarni S, Treleaven J, Saso R, Mehta J. Long-term follow-up of relapsed acute leukemia treated with immunotherapy after allogeneic transplantation: the inseparability of graft-versus-host disease and graft-versus-leukemia, and the problem of extramedullary relapse. Leuk Lymphoma 1999; 32: 505-12.

15. Care RS, Valk PJ, Goodeve AC, et al. Incidence and prognosis of C-KIT and FLT3 mutations in core binding factor (CBF) acute myeloid leukaemias. Br J Haematol 2003; 121: 775-7.

16. Kottaridis PD, Gale RE, Frew ME, et al. The presence of a FLT3 internal tandem duplication in patients with acute myeloid leukemia (AML) adds important prognostic information to cytogenetic risk group and response to the first cycle of chemotherapy: analysis of 854 patients from the United Kingdom Medical Research Council AML 10 and 12 trials. Blood 2001; 98: 1752-9.

17. Paschka P, Marcucci G, Ruppert AS, et al. Adverse prognostic significance of KIT mutations in adult acute myeloid leukemia with inv(16) and t(8;21): a Cancer and Leukemia Group B Study. J Clin Oncol 2006; 24: 3904-11. 